Author's Note: An excellent resource for long term care providers is the Widener University consortium on aging and sexuality (http://www.widener.edu/academics/schools/shsp/hss/sex_aging/default.aspx) 


\section{Sexuality in Older Adults}

Hillman (2012) describes the predominant portrayal of older adults in the U.S. as helpless, depressed and sexless; all apart of ageism in our society. To support her view she offers a review of several studies in which younger adults, adult children of older adults, health care practitioners and even older adults themselves deride sexuality in older people. Our youth culture defines sexuality as hard, beautiful bodies, focused more on arousal than intimacy or relationships. More recently, television and film that have portrayed older adult sexuality have focused on relationship quality, and sexuality as part of intimate communication among older couples. However, much of it is in the context of selling products to treat erectile dysfunction. In most popular ads, or greeting cards, for instance, older adults are portrayed as rigid, helpless, out of touch buffoons.

One of the largest studies of older adult sexuality was published in the New England Journal of Medicine (Lindau et al., 2007). The study included a survey of 3005 adults ages 57-85 years. Slightly more than half of the sample were women. Sexual intercourse, while remaining present in advanced ages, demonstrated a decline with age. Among those 57-64 years old $75 \%$ of the sample reported being sexually active. This percentage dropped to $50 \%$ in those $65-74$ and to $26 \%$ in those over the age of 75 years. There were clear gender differences with women reporting less sexual activity at all ages, and also reported significant levels of sexual dissatisfaction due to inability to climax (34\%), low desire (39\%) and difficulty with vaginal lubrication $(43 \%)$. Thirty seven percent of older men reported erectile dysfunction. Overall $14 \%$ of men reported using medications or supplements, while more men reported talking with their physician about sexual difficulty (38\%) than did women $(14 \%)$.

The data from Lindau and colleagues (2007) also reflect what experienced clinicians who work with older adults already know; there is a significant "partner gap" or availability of sexual partners as people grow older. While $80 \%$ of women and men ages $45-59$ years old report having a partner available for sex, only $21 \%$ of women over age 75 and $58 \%$ of men over age 75 reported having a partner available. Lindau's study results echoed previous survey findings that decline in sexual activity was more related to the "male factor" (see Zeiss, Zeiss and Davies, 1999). Men's own health conditions such as pain, arthritis, stroke, and dementia and widowhood for women were main factors in decline in sexuality activity, whereas widowhood for men was unrelated to their sexual activity.

\section{Older Adult Communication about Sexuality with Physicians}

Zeiss, Zeiss and Davies (1999) reported that older adults have much hesitancy about discussing sexual concerns with their primary care physicians. Older adults fear that physicians will dismiss their concerns as psychosomatic. They also fear that their physicians will not be comfortable talking about sexual concerns, and finally, that their physicians will hesitate to provide treatment options for older adults. In fact, Zeiss, Zeiss and Davies claim that older adults prefer their health care provider to bring up sexual issues as part of their inquiry into the older adult's health. The authors offered a number of open-ended questions that health care providers can use with older adults including: 
- What changes in physical intimacy have you experienced as you have grown older?

- What health problems have affected your ability to be physically intimate?

- How have any changes in sexual function influenced other aspects of intimacy?

- What goals do you have for your intimate relationship?

Zeiss, Zeiss and Davies had some other specific questions for older adults who are single. These included:

- What are your wishes regarding having an intimate relationship in your life at this time?

- What do you experience in regard to desire for sexual activity or sexual satisfaction?

- What are some of the ways you are able to express your sexual interests or sexual satisfaction?

\section{Sexuality in Long Term Care}

Over two million older adults live in nursing homes or assisted living facilities, making it vital that sexual needs addressed (Hillman, 2012). While many administrators or even health providers would be surprised that sexual issues remain a concern for older adults in long term care, Hillman summarized survey findings that indicated that issues ranging from touching, kissing, to masturbation, and intercourse remain important to long term care residents. Lichtenberg (1993) summarized many of the early studies that demonstrated that while about $10 \%$ of residents indicated an interest in being sexually active, when staff was surveyed, their perceptions were the opposite, reporting that the percentage of residents who engaged in sexual talk, groping or publically masturbating in front of staff was three times greater than those who reported sexual interest. Chief among the issues for older adults in long term care is privacy and capacity to give consent for intimate relationships (ABA-APA, 2008; Lichtenberg, 1997). Much of the rest of this article will focus on the issue of capacity to participate in intimate relationships, and what best practices now exist.

Dementia in later life affects many long term care residents. In many respects, brain dysfunction often reduces initiation and increases apathy and thereby reduces sexual expression in an older person with dementia. In some cases, however, dementia increases disinhibition and hyper-sexuality. Nevertheless, there is a reserve of a continued need for intimacy and an interest in sexual satisfaction found in most persons with dementia. Physical intimacy is a profound human need that cannot be replaced by other relationships such as friendships. Balancing the needs of older residents to be involved with physical intimacy, while simultaneously protecting the older adult residents from coercion and exploitation, is a major dilemma facing most long term care organizations.

In my experience in working in several nursing homes and in reviewing several cases of alleged sexual exploitation in the long term care setting, leadership at facilities often take extreme or all or none positions. On the "pro sexuality" side, administrators point out that sexual activity increases life satisfaction, reduces loneliness and depression and prolongs 
life. They point to ethical issues around autonomy of the individual, in addition to the basic human need and health of older adults. A typical case in which the "pro sexuality" atmosphere fails to protect older adults is as follows. A less cognitively impaired male resident approaches a more cognitively impaired woman or women, and attempts to initiate sexual contact. The staff argues that the individuals have a "special" relationship, only to later learn that the woman acquiesced because she mistakenly believed the man to be her husband. When the husband learns of the sexual activity he files a complaint with the state.

On the "anti-sexuality" side, administrators point to the risks of sexual exploitation, possibility of increasing sexually transmitted diseases, and lifetime values of modesty that many older adults appear to have. It is rarer for treatment teams to take each case and assess it more fully to determine whether there is legitimate autonomy in the older adult or whether there is a high risk of exploitation. Residents often have a guardian and thus many long term care professionals assume this means they lack legal capacity to participate in intimate relationships. Many older adults in long term care lack the ability to communicate well, and thus it is assumed that no assessment can effectively elicit key information relative to capacity. Finally, many administrators are concerned, with good reason, that allowing sexuality in older adult residents will lead to legal charges of abuse and or facility investigations by their state. The assumed lack of capacity in older residents coupled with the fear of reprisals lead the facility to deprive those older adults who do have capacity to engage in sexual activity; an action that can and does cause harm.

\section{Assessment of Capacity to Participate in an Intimate Relationship}

My colleague, Deborah Strzepek and I helped to create a co-ed Alzheimer's unit in the late 1980 's. It was not long into our work on the unit that a new, intimate relationship emerged, and soon thereafter others emerged as well. There are no universally accepted criteria for capacity to consent in sexual relations, but the simple fact of having a guardian does not rule out the possibility that the older adult can consent to engage in intimate relationships. We decided to create a semi-structured interview approach to assess capacity to participate in intimate relationships (Lichtenberg \& Strzepek, 1990); a tool that remains the only formal capacity assessment tool in this area (ABA-APA, 2008, Hillman, 2012). Others have developed guidelines but no further assessment tools have been developed.

There are typically several considerations that must be taken into account before determining that an older adult does not have capacity to participate in intimate relationships. These include:

1. A mental health and/or neurocognitive condition is present.

2. Decisional Abilities are affected by the condition in \#1.

3. Legal standards are integrated into the decision based on findings from \#1 and \#2.

4. Burden of proof is on those alleging incapacity.

5. Capacity is not global but always specific to the decision in question. 
Thus. the key to the capacity analysis in older adults in long term care settings who suffer from dementia are the integrity of the individual's decisional abilities. It is now well accepted that one aspect of most capacity issues is the integrity of decisional abilities (Appelbaum \& Grisso, 1988; ABA-APA, 2008). What are these decisional abilities? The older adult must be able to meet the following:

1. Communicate choice,

2. Communicate understanding of the choice,

3. Communicate appreciation of potential consequences of the choice, and

4. Communicate reasoning and rationale of the choice.

Finally, these decisional abilities should be integrated with what we know about the older person's values.

We built our assessment tool around these decisional abilities. First, we assumed the older adult must have a basic level of cognitive functioning to meet true capacity standards and we chose a Mini Mental State Examination (Folstein, Folstein \& McHugh, 1975) (MMSE) score of 14 as our cutoff. Second, an interviewer of the same sex as the older adult would conduct a semi-structured interview inquiring into the following criteria.

1. Awareness of the relationship (Choice and Understanding):

- Know who the partner is,

- Know the partner is not spouse,

- Aware of who is initiating sexual contact, and

- State the level of intimacy to which she or he is comfortable.

Does the older adult know who the sexual partner is, and can the older adult accurately state the relationship status or does the older adult perceive the partner as a spouse? Can the older adult communicate who is initiating the sexual contact, and state the level of intimacy it which they are comfortable. These questions assess the older adult's ability to communicate a choice and an understanding of the relationship.

2. Ability to avoid exploitation (Reasoning/Rationale):

- Knows about relationship,

- Knows what one wants from the relationship, and

- Has ability to set limits if wants to (e.g., saying no).

Can the older adult communicate knowledge about the relationship and what the older likes or dislikes about the relationship? Can the older adult communicate what he or she wants from the relationship at this time, and how comfortable he or she is with those wants? Finally, and especially for women who have dementia, can the older adult set limits on how sexual the physical intimacy becomes if they want to? How confident is the older person that she would be able to say "no" to unwanted sexual advances and have her wishes respected. 
3. Resident is aware of potential risks (Awareness of Potential Consequences)

- That relationship may be time-limited, and

- How might one react when relationship ends.

Long-term care settings are no longer settings where older adults typically go to and stay for the remainder of his or her life. Often there are changes in settings due to care needs or preferences of the family. Thus, the potential for the relationship to be time limited is real and in many cases very likely. Does the older person have an awareness of this, and how devastating will the loss of the relationship be the individual? How might the older person react to this type of loss; a question asked more for clinical reasons than for determining capacity itself. These decisional abilities about intimate relationships should be integrated into the other steps of capacity evaluations and a judgment made by a health care professional empowered by the facility to make these assessments. A summary of the assessment process is contained in Table 1.

\section{Case examples}

Case Example \# 1: A demented widowed woman in her 70's living in a long term care facility, is depressed and still grieving the loss of her husband 10 years earlier, began to perk up when she became the object of a 70-year-old male's attention. The man had been married three times and had the reputation of being a ladies' man. At the beginning of the relationship, both residents seemed happier and could be seen walking up and down the halls arm in arm; they kissed and fondled as well. Both expressed great pleasure in the relationship. She said he filled an "empty place" in her heart, and he repeatedly stated what a "fine" woman she was. They also spent a lot of time talking to each other and clearly enjoyed a social relationship.

On the Mini Mental State Exam, he had a score of 20 and she a score of 21. On interview, both patients appeared to be cognizant of the identity and intent of the other. He wished for intercourse, but she did not. It was clear the she could and had said no to unwanted sexual contact, and he respected her limits. She was capable of saying she did not want to get in too deep and get hurt. He was clear about his wishes and also realized the relationship might not last. The staff agreed that both patients were competent and allowed them the sexual contact with the mutual limits set by the couple.

Case Example \#2: In this case, a sexual relationship was denied between a married couple. Mr. M was a 78-year-old retired accountant, and his wife was a 74-year-old retired custodial worker. The couple met after Mr. M's 30-year marriage ended when he was widowed. For the first four years of their marriage, their relationship was a good one. She then, however, became demented. He, in turn, became angry and physically abusive toward her. As her dementia increased, he also became mildly demented. Social services responded to many complaints from their neighbors, but could not be awarded guardianship by the court. Finally, due to neglect, Mrs. M was hospitalized and sent to long-term care after discharge. Mr. $\mathrm{M}$ also entered long-term care a year later when social services was awarded guardianship. While the couple did not occupy the same room, they were placed on the same long term care unit. 
Mr. M resumed his abusive manner toward his wife. She was compliant to all of his demands. Her behavior, however, deteriorated as she became? uncooperative with staff and appeared depressed. Mini Mental State scores were 22 for Mr. M and 8 for Mrs. M. During the interview it was clear that Mrs. M could not avoid exploitation and privately stated that she did not want a sexual relationship with her husband. Mr. M, interestingly, confided that, although he had engaged in sexual relations with his wife in long-term care, he was not eager to continue this practice. Due to her incompetence, the staff agreed to monitor the couple and prevent sexual intercourse.

In summary, our approach remains a clinical tool, and has as its goal to assess capacity but does not have as its goal to be the ultimate determiner of whether the intimate relationship is sanctioned. If the older adults in the relationship do have capacity, then we feel strongly that the older adults should not only be permitted, but be assisted in participating in an intimate relationship. Our assessment method does not state nor imply that all older adults without capacity should not engage in intimate relationships. Rather, the lack of capacity should be recognized and a set of careful decisions should then be made.

In 2009, the Vancouver Coastal Health Authority came out with guidelines about how to proceed with intimate relationship decision-making when one or both older adults display a lack of capacity to participate in an intimate relationship. The explicit values of the Guidelines and objectives included:

- Care facilities have an ethical and legal obligation to recognize, respect, and support clients' sexual lives.

- Guidelines are intended to guide care facilities in knowing how best to support healthy sexuality with their clients while supporting staff and care providers

Some of the questions suggested in the guidelines included:

- What types of sexual expression can be supported in care facilities?

- How should sexual relationships between persons with compromised cognitive function be addressed?

- How can possible harm that may result from sexual activity be mitigated?

- How can sexual expression be promoted with clients who have physical disabilities?

- What happens when conflict arises between the personal values of clients and those of a staff member or the institution?

- What if family members do not support the client's sexual activity?

- What does the law have to say about clients engaging in paid-for sexual services in care facilities?

- How can the privacy needs of clients be met?

- What kind of staff training and support would be helpful? 
If the older adult is deemed to lack capacity, then a team is formed including a family representative to determine whether the intimate relationship is permitted. A summary of the process includes:

- If a person has been appointed by the court or the client to make decisions specifically about sexual activity, then that person is the decision maker.

- If there is no one with legal authority to make the decisions, then the family/ committee/representative and the care facility jointly determine whether sexual activity is in the best interest of the client.

- Allow inclusion of the client in the decision-making process as much as possible

\section{Recommendations for Long Term Care Facilities}

It is critically important to create staff policies about sexuality and capacity assessment in long term care facilities. Not only do these policies need to be written, but there should also be annual trainings, and encouragement of case discussions throughout the year. Sexuality, sexual needs and desires should be assessed during the initial nurse or physician assessment with the resident. It is important to demonstrate to residents that there is an awareness and openness to the sexual health of the residents. The facility needs an overall plan to encourage an atmosphere where privacy of residents is respected. Documentation of intimacy issues and relationships is important, and staff training on how to document these, and to insist on documentation of these is critical. Finally, family members need to be brought into the discussion surrounding resident intimacy issues, often needing to be educated about these needs and how the facility supports its older residents. Finally, reducing extreme responses, either pro or anti sexuality in older residents is critical for a health atmosphere within the facility. Sexual needs are unique and real, even in frail or demented older adults, and these need to be balanced with the need for protection frail and demented older adults have with regard to becoming sexually exploited.

\section{Implications for Occupational Therapy}

Occupational therapists, by virtue of their professional roles including addressing activities of daily living tasks for example, are often around patients during acts of intimate care (e.g. toileting, bathing, dressing), and therefore, there may be more opportunities to approach the topic of intimacy and sexuality goals and desires of patients. It is important for occupational therapy practitioners also, not just to bring up these topics but to proactively ask patients whether they are in a relationship with a partner who is resides inside or outside of the facility. Holistic care must include the occupational therapy practitioners' inclusion of sexual needs and concerns of older adults, and in fact, due to their training in holistic, and person-centered approaches the practitioner may often be in the best position to broach sexuality with older patients in long term care facilities.

\section{References}

American Bar Association Commission on Law and Aging. American Psychological Association. Assessment of older adults with diminished capacity: A handbook for psychologists. American Bar Association; Washington, DC: 2008. 
Folstein M, Folstein S, McHugh P. Mini Mental State: A practical method for grading the cognitive state of patients for the clinician. Journal of Psychiatric Research. 1975; 12:189-196. [PubMed: 1202204]

Hillman, J. Sexuality and Aging. Springer; New York: 2012.

Lichtenberg PA, Strzepek DM. Assessments of institutionalized dementia patient's competencies to participate in intimate relationships. The Gerontologist. 1990; 30:117-120. [PubMed: 2311954]

Lichtenberg PA. Clinical perspectives on sexual issues in nursing homes. Topics in Geriatric Rehabilitation. 1997; 12:1-10.

Vancouver Coastal Health Authority. Supporting Sexual Health and Intimacy in Care Facilities: Guidelines for Supporting Adults Living in Long-Term Care Facilities and Group Homes in British Columbia. Canada: 2009.

Zeiss, AM.; Zeiss, RA.; Davies, H. Assessment of sexual function and dysfunction in older adults (pp 270-296). In: Lichtenberg, PA., editor. Handbook of Assessment in Clinical Gerontology. Wiley Press; New York: 1999. 


\begin{tabular}{|c|c|c|}
\hline \multirow{7}{*}{ 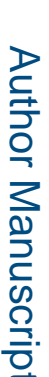 } & \multicolumn{2}{|c|}{ Mini Mental State score greater than 14} \\
\hline & Yes & No \\
\hline & $\begin{array}{c}\text { Perform assessment } \\
\text { interview }\end{array}$ & $\begin{array}{l}\text { Patient unable to } \\
\text { consent }\end{array}$ \\
\hline & \multicolumn{2}{|c|}{ Patient's ability to avoid exploitation } \\
\hline & Yes & No \\
\hline & $\begin{array}{l}\text { Continue } \\
\text { evaluation }\end{array}$ & $\begin{array}{l}\text { Patient unable to } \\
\text { consent }\end{array}$ \\
\hline & \multicolumn{2}{|c|}{ Patient's awareness of the relationship } \\
\hline & Yes & No \\
\hline & $\begin{array}{l}\text { Continue } \\
\text { evaluation }\end{array}$ & $\begin{array}{l}\text { Patient unable to } \\
\text { consent }\end{array}$ \\
\hline & \multicolumn{2}{|c|}{ Patient's awareness of risk } \\
\hline & Yes & No \\
\hline & $\begin{array}{l}\text { Consider patient } \\
\text { competent to } \\
\text { participate in an } \\
\text { intimate } \\
\text { relationship }\end{array}$ & $\begin{array}{l}\text { Provide frequent } \\
\text { reminders of risks } \\
\text { but permit } \\
\text { relationship }\end{array}$ \\
\hline & & \\
\hline
\end{tabular}

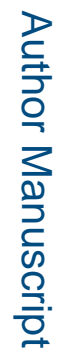

를

Occup Ther Health Care. Author manuscript; available in PMC 2015 August 26. 